\title{
PUSAT KULINER BERKELANJUTAN DI PANTAI INDAH KAPUK
}

\author{
Giacinta Fabiola ${ }^{1}$, Diah Anggraini ${ }^{2)}$ \\ 1) Program Studi S1 Arsitektur, Fakultas Teknik, Universitas Tarumanagara, giacintafabiola@yahoo.com \\ 2) Program Studi S1 Arsitektur, Fakultas Teknik, Universitas Tarumanagara, diaha@ft.untar.ac.id
}

\begin{abstract}
Abstrak
Perubahan pola perilaku manusia yang paling fundamental disebabkan oleh makanan. Hal tersebut sudah terjadi semenjak masa Hunter Gatherer, Agricultural Revolution, Industrial Revolution dan masa kini. Millennial menjadi subyek utama bahasan dari penelitian ini. Maka fokus isu yang diangkat adalah "Bagaimana Millennial Memperlakukan Makanan?". Lokasi proyek berada di Jl. Pantai Indah Kapuk, Jakarta Utara yang sudah menjadi ikon sebagai daerah pusat kuliner dari segala kalangan generasi. Lokasi tapak berada di antara perkantoran, perumahan dan komersil yang memiliki pergerakan mobilitas pedestrian yang tinggi setiap harinya. Tujuan dari proyek ini adalah ingin ikut serta dalam memberikan fasilitas yang dibutuhkan oleh kota terutama sekitar tapak proyek sebagai linkage di antara fungsi bangunan lainnya dan mencoba mengubah eating habits generasi Millennial yang lebih mendukung gerakan Sustainable Development Goals perihal Zero Hunger serta dapat menjaga kualitas ekologi setempat dengan cara mengurangi sampah makanan dan plastik. Metode penelitian yang digunakan pada penelitian ini adalah Tipology, Pattern Language, Phenomenology dan Survey Lapangan. Hasil penelitian yang didapatkan adalah mendesain bangunan sebagai "Pusat Kuliner Berkelanjutan di Pantai Indah Kapuk/ Sustainable Food Hub at Pantai Indah Kapuk". Proyek ini memiliki 4 program utama yaitu Restaurant \& Café, Growing Field Area, Education Platform, \& Sustainable Food Utensils Shop yang bertujuan memperbaiki Millennial's eating habits serta Linkage sebagai bentuk tanggapan proyek terhadap kebutuhan akan jalur pedestrian di sekitar tapak sehingga proyek bisa memberikan kontribusi bagi kota.
\end{abstract}

Kata kunci: Berkelanjutan; Kuliner; Millenial; PIK

\begin{abstract}
The most fundamental changes in human behavioral pattern is caused by food. These changes happened since Hunter Gatherer period and evolve through Agricultural Revolution period, Industrial Revolution period, and it is still happening now. The main subject of this research is Millennials and it focuses on "How do Millenials Treat Their Food?" issue. This project is located at Pantai Indah Kapuk (PIK) Boulevard, North Jakarta which is an iconic place that serves as a culinary center for all generations. Project site is located between office complex, housing, and commercial area that has high mobility of pedestrians. The purpose of this project is to participate in giving the town the facility that it needs especially the area surrounding project site as linkage between other buildings functions and encouraging a change in Millennials' eating habits that supports Sustainable Development Goals regarding Zero Hunger, also to preserve local ecological quality through food and plastic waste reduction. This research use Tipology, Pattern Language, Phenomenology and Field Survey research methodologies. The result of this research is designing a building as "Sustainable Food Hub at Pantai Indah Kapuk". This project consists of 4 main programs which is Restaurant \& Café, Growing Field Area, Education Platform, and Sustainable Food Utensils Shop that has a purpose of improving Millennials' Eating Habits. It also serves as a linkage around project site as a form of project's contribution and response to the town need for pedestrian lane.
\end{abstract}

Keywords: Culinary; Millennials; PIK; Sustainable 


\section{PENDAHULUAN}

Makanan merupakan aspek yang paling dasar dan fundamental bagi kebutuhan manusia. Semenjak masa Hunter Gatherer, Agricultural Revolution sampai Industrial Revolution memberikan dampak yang besar terhadap perubahan perilaku manusia. Sementara itu struktur demografi di Indonesia khususnya Jakarta, saat ini didominasi mereka yang berusia 18-30 tahun, yang kemudian dijuluki Generasi Millennial. Ciri karakteristik mereka melahirkan gaya hidup millennial, termasuk dengan cara mereka menikmati dan memperlakukan makanan. Studi ini difokuskan pada kajian tentang "Eating Habits" pada Millennial yang kemudian mempengaruhi warna dan ciri kuliner di Jakarta.

Jakarta merupakan Ibu Kota Indonesia yang berciri kota metropolitan, dengan jumlah penduduk yang besar serta mempunyai latar belakang sosial, ekonomi dan budaya yang heterogen. Memiliki potensi yang sangat besar karena merupakan pusat berbagai kegiatan seperti pemerintahan, perkonomian, pendidikan, budaya dan sebagainya. Terdiri dari 5 wilayah administrasi yaitu Jakarta Utara, Jakarta Timur, Jakarta Selatan, Jakarta Barat dan Jakarta Pusat. Namun lokasi yang akan diambil pada proyek ini adalah Jakarta Utara karena memiliki sejarah sebagai kawasan perdagangan. Pada abad ke-5, wilayah Jakarta Utara sudah menjadi pusat pertumbuhan Kota Jakarta di muara sungai Ciliwung Angke, tepatnya di kawasan Pantai Indah Kapuk.

Dalam perkembangannya saat ini, Pantai Indah Kapuk (PIK) menjadi salah satu daerah yang iconic di Jakarta Utara. Merupakan tempat yang menyediakan makanan dengan banyak variasi. Keunikan dan ciri khas daerah ini bisa dinikmati oleh segala jenis umur dan generasi. Salah satu generasi yang paling familiar dengan PIK adalah generasi Millennial. Generasi ini memiliki eating habits/ kebiasaan dalam mengkonsumsi makanan yang cukup unik dan berbeda jika dibandingkan dengan generasi-generasi sebelumnya. Beberapa eating habits generasi Millennial berdasarkan kajian teori dan studi pengamatan lapangan adalah Connected, Buy Experience, Food and Plastic Waste dan Unhealthy Food Consumption.

Visi dari proyek ini adalah mengubah eating habits generasi Millennial sehingga dapat memberikan dampak global yang baik dalam mendukung gerakan Sustainable Development Goals perihal Zero Hunger serta menjaga kualitas ekologi dengan cara mengurangi sampah makanan dan plastik serta menjaga kelestarian hutan bakau bagi keseimbangan ekologi setempat agar kota dapat bersifat sustainable. Selain itu, visi lainnya adalah memberikan perubahan baik bagi generasi Millennial agar dapat memiliki kualitas kesehatan dan produktivitas yang baik. Misi dari proyek ini adalah memperbaiki kebiasaan lama menjadi yang lebih baik yaitu dengan cara mendukung local farmers dan markets setempat, mengurangi pembuangan sampah makanan di Jakarta sebagai salah satu bentuk kontribusi proyek untuk mendukung gerakan SDG-Zero Hunger, mengurangi pembuangan sampah plastik di Jakarta agar ekologi setempat menjadi lebih stabil, dapat menciptakan dan membiasakan diri dengan konsep sustainable eating habits dengan hasil desain proyek dan media edukasi.

\section{KAJIAN LITERATUR}

\section{Pola Perubahan Perilaku Manusia}

Tipe dan perilaku merupakan suatu hal yang saling berkesinambungan. Menurut Yuval Noah Harari dalam bukunya yang berjudul "Sapiens" tahun 2014, perubahan perilaku manusia yang paling mendasar diakibatkan oleh makanan.

Pada masa Hunter Gatherer, manusia (Sapiens) berpindah-pindah (nomaden) untuk mencari sumber makanan agar dapat bertahan hidup. Pendapatan energi setiap harinya bersifat tidak menentu sehingga manusia pada masa itu harus bisa melakukan segala hal (mandiri). Sekitar 300.000 tahun lalu, Homo Erectus, Neanderthals dan Homosapiens menggunakan api untuk kesehariannya, salah satunya adalah memasak. Setelah itu manusia mulai memasuki Agricultural Revolution di mana sudah memiliki perubahan perilaku menjadi menetap dan memiliki pembagian klasifikasi akan pekerjaan yang dilakukan. Hal ini dilakukan akibat dari manusia sudah masuk ke tahap Cognitive Revolution dan memiliki pandangan 
bahwa akan lebih baik jika setiap harinya bisa mendapatkan makanan dengan jumlah yang stabil sehingga dapat memenuhi kebutuhan energi manusia. Industrial Revolution merupakan salah satu efek dari perkembangan Agricultural Revolution dan kota. Makanan yang diproduksi sangat berlimpah dan lama kelamaan akan terbuang sia-sia karena tidak mampu untuk dikonsumsi semua. Sehingga Industrial Revolution menjadi salah satu solusi untuk menghasilkan output makanan lainnya dengan sumber yang sama menggunakan teknologi.

Sekarang keadaan kota sudah semakin kompleks. Ciri-ciri urbanitas saat ini adalah adanya pergeseran komposisi penduduk urban-rural, penduduk kelas menengah dan penduduk muda.1 Kemajuan teknologi dan informasi yang mempengaruhi gaya hidup (lifestyle) manusia terutama generasi Millennial dan generasi Z. Salah satu contohnya adalah kebiasaan makan di luar atau menggunakan aplikasi untuk memesan makanan. Maraknya gerakan menggunakan transportasi umum seperti ojek online (Gojek dan Grab), Transjakarta, bus kota, kereta dan MRT. Pedestrian sudah menjadi aspek penting dalam pembangunan kota. Salah satu contohnya adalah adanya rencana revitalisasi jalur pedestrian di MH-Thamrin dengan konsep Sabuk Nusantara di mana terdapat ruang-ruang ekspresi berbagai budaya nusantara. 2

\section{Permasalahan Kesejamanan}

Memasuki abad ke - 21, sudah tidak aneh lagi jika teknologi dan informasi berkembang secara pesat dan mengubah perilaku manusia. Andi Sandbergs (2009), peneliti futuris Swedia, menggambarkan arketipe keruangan manusia hari ini dalam rupa diagram jaringan dan menyebutnya jagat para infonaut yaitu istilah yang muncul pada 1985 untuk menggambarkan generasi yang mengalami kemajuan dari revolusi teknologi komputer dan sangat mengandalkan pertukaran informasi berbasis internet.

Tabel 1. Perbandingan Diagram Arketipe Pada Masa Hunter Gatherer dan Jagat Infonaut

\begin{tabular}{|c|c|}
\hline 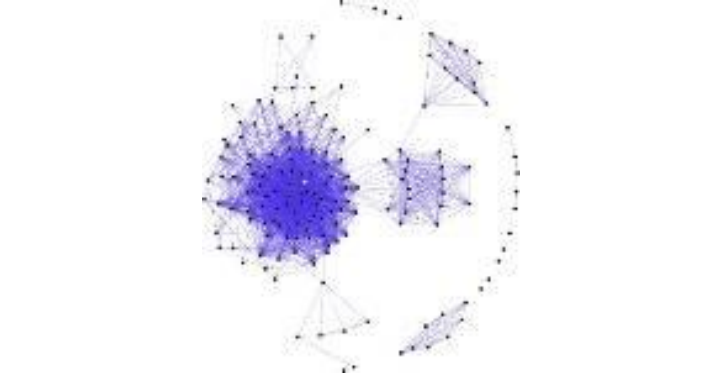 & (3) \\
\hline $\begin{array}{c}\text { Diagram Arketipe Spasial “Jaringan” di Era Para } \\
\text { Infonaut } \\
\text { Sumber: Anders Sandbergs, } 2009\end{array}$ & $\begin{array}{c}\text { Diagram Arketipe Spasial "Sensitive Chaos" } \\
\text { Sumber: Spatial Archetypes: The Hidden Patterns } \\
\text { of Psyche and Civilization, } 1983 .\end{array}$ \\
\hline $\begin{array}{l}\text { Menggambarkan keadaan di mana semua saling } \\
\text { terhubung antara } 1 \text { titik dengan lainnya. } \\
\text { Menggambarkan ketidakpastian hubungan antar } \\
\text { titik-titik yang berisi informasi yang bersifat } \\
\text { global. Memiliki probabilitias yang sangat } \\
\text { banyak. }\end{array}$ & $\begin{array}{l}\text { Menggambarkan ketidakpastian tata ruang di } \\
\text { masyarakat yang masih mengandalkan berburu } \\
\text { dan mengumpulkan makanan. }{ }^{3}\end{array}$ \\
\hline
\end{tabular}

Kedua diagram di atas sama-sama menggambarkan suatu bentuk ketidakpastian yang masing-masing memiliki penyebab yang berbeda. Pada era jagat Infonaut, terjadi ketidakpastian pertukaran informasi yang bersifat global dan saling terhubung. Sedangkan pada masa Hunter Gatherer, terjadi ketidakpastian tata ruang pada masyarakat akibat dari

\footnotetext{
${ }^{1}$ Indonesia 2020 : The Urban Middle Class Millennials

${ }^{2}$ https://www.idntimes.com/news/indonesia/akhmadmustaqim/saksikan-begini-kerennya-jalur-pedestrian-di-jalan-thamrin/full

${ }^{3}$ Buku Soal TGA 8.27 halaam 12. Studio Perancangan Arsitektur 8, Universitas Tarumanagara.
} 
pola berburu dalam mengumpulkan makanan (nomaden). Michel Focault dalam bukunya yang berjudul "Knowledge and Power" menjelaskan bahwa pengetahuan merupakan bentuk kekuasaan yang sangat luar biasa. ${ }^{4}$ Kekuasaan dibagi menjadi 2 yaitu old money dan knowledge. Sekarang currency di dunia sudah bukan lagi berbentuk dollar, melainkan informasi. Yuval Noah Harari dalam bukunya yang berjudul "Homo Deus" memprediksi bahwa manusia akan berevolusi dari Homo Sapiens menjadi Homo Deus jika manusia terus terjerat di dalam arus perubahan informasi dan teknologi. Situasi ekstrim ini membuat segala keputusan berasal dari satu central processor yang berisi data. ${ }^{5}$ Selain itu, Yuval juga memprediksikan bahwa beberapa dekade ke depan, akan terjadi Internet-like Revolutions di mana teknologi dapat menguasai politik. Artificial Intelligence (Al) dan Biotechnology akan memasuki pasar ekonomi dan mempengaruhi aspek sosial manusia. ${ }^{6}$

\section{Millennial}

Merupakan nama lain dari generasi $Y$ yang lahir pada tahun 1981 -1994. Jika dihitung sekarang pada tahun 2019, Millennial sudah berumur 25-38 tahun. Millennial memiliki 3 karakter utama secara general yaitu Creative, Connected dan Confidence. ${ }^{7}$ Millennial merupakan generasi yang kreatif karena dapat berpikir out of the box sehingga bisa menghasilkan hasil karya yang unik dan inovatif. Kemudahan mendapatkan dan memberikan informasi (era Jagat Infonaut) disertai dengan perkembangan internet dan teknologi membuat mereka saling terhubung. Millennial juga memiliki kepercayaan diri yang tinggi dikarenakan generasi ini cenderung dapat membawa dirinya dalam image yang baik dan sempurna yang akan melahirkan budaya sendiri yaitu budaya narsisme.

Akibat dari karakter dan kebiasaan Millennial yang selalu update akan informasi dan selalu terhubung dengan internet menyebabkan Millennial menjadi gemar untuk mengeksplorasi pengalaman baru dan dapat mengabadikannya dengan mengambil foto atau video. Tradisi atau kebiasaan ini sangat trending di kalangan generasi Millenial dan salah satunya adalah eksplorasi makanan-minuman yang lagi trending. Sekarang banyak sekali aplikasi di internet ataupun gadget yang dapat mendata informasi mengenai makanan dan minuman yang sedang trending sekarang seperti Zomato, Google, Instagram, Facebook dan lainnya. Namun akibat dari tradisi/ kebiasaan ini, generasi ini menjadi memiliki kebiasaan yang buruk memperlakukan makanan yang memberi dampak terhadap lingkungan seperti food waste dan peningkatan sampah plastik, kertas, tissue, dan lainnya.

Menurut artikel Urban Middle-Class Millennials di Indonesia tahun 2020 diperoleh proyeksi populasi urban middle-class millennials pada tahun 2020 sebesar 35 juta jiwa atau 13\% dari jumlah penduduk Indonesia tahun 2020 yang diproyeksikan sebesar 271 juta jiwa. Selain memberikan efek yang besar terhadap perubahan sosial dan ekonomi, generasi ini juga sangat berpengaruh besar terhadap urban planning kota. Sekitar 62\% generasi Millennial memilih untuk tinggal di mixed-use communities (shops, restaurants and offices) yang dekat dengan tempat tinggalnya. ${ }^{8}$ Cara kerja yang fleksibel dan bisa di mana saja (digital nomade) membuat generasi ini cenderung untuk bekerja di kantor dengan pola yang sesuai dengan cara kerjanya. Ditambah dengan dukungan fasilitas kota seperti public transportation, mixed-use communities, and a pedestrian-friendly environment akan menjadi parameter-parameter yang sangat berpengaruh terhadap urban planning ke depannya.

Menurut Yuval Noah Harari dalam bukunya yang berjudul " 21 Lessons for $21^{\text {st }}$ Century", kita sebagai manusia telah mengambil banyak sumber daya alam dari lingkungan namun kita mengembalikannya kembali dengan jumlah yang luar biasa besar akan pembuangan limbah

\footnotetext{
${ }^{4}$ Fer Bas. 2018. Anatomi Pemikiran Michel Foucault: Wacana dan Kekuasaan (Discourse and Power) di http://febasfi.blogspot.com/2013/07/anatomi-pemikiran-michel-foucault.html

${ }^{5}$ Yuval Noah Harari - Homo Deus:a Brief of Tomorrow, halaman 215

${ }^{6}$ Ibid, halaman 218

${ }^{7}$ Indonesia 2020 : The Urban Middle Class Millennials

${ }^{8}$ https://www.architectmagazine.com/design/urbanism-planning/study-millennials-impact-on-workplace-design-and-urbanplanning_o
} 
dan racun yang dapat mengubah komposisi tanah, air dan atmosfer. ${ }^{9}$ Jika ekologi kita terganggu, maka kegiatan agrikultur pun tidak akan berjalan dengan baik. Jika hal tersebut terjadi, manusia akan mengalami perubahan keadaan dan perilaku yang drastis seperti contoh meningkatnya angka kemiskinan, kelaparan dan lainnya. Dunia sudah mulai waspada akan hal ini, sehingga mulai diselenggarakan kampanye atau gerakan-gerakan untuk memperbaiki dunia ini. Salah satu contohnya adalah Sustainable Development Goals (SDG). Zero Hunger merupakan Goals ke-2 di SDG. Generasi Millennial dapat menjadi motor penggerak dan masing-masing individu dapat memberikan perubahan akan dunia ini yaitu mengubah kebiasaannya dengan mendukung local farmers atau markets, making sustainable food choices, supporting good nutrition for all, fighting food and plastic waste dan menyebarkan informasi yang baik dan benar akan pentingnya makanan bagi dunia sehingga Zero Hunger dapat menjadi kenyataan di kemudian hari.

\section{Tipologi}

Tipologi merupakan diskursus atau ilmu yang berkenaan dengan tipe. ${ }^{10}$ Tipe dapat dideskripsikan sebagai suatu bentuk umum, struktur, atau karakter yang membedakan jenis, kelompok tertentu. Sebagai suatu pola atau model. ${ }^{11}$ Berdasarkan penjelasan dari Yuval Noah Harari di dalam bukunya yang berjudul "Sapiens", terdapat perubahan pola makan dari jaman Hunter Gatherer, Agriculture Revolution, Industrial Revolution sampai jaman sekarang. ${ }^{12} \mathrm{Hal}$ ini bisa disebutkan sebagai tipologi perkembangan pola makan. Tentunya selain terdapat pekembangan pola makan setiap jamannya, terjadi perubahan tipologi tempat makan itu sendiri. Hal ini berkaitan dengan ranah arsitektur sebagai wadah dari kegiatan makan yang menghasilkan perilaku dan aktivitas yang berbeda-beda.

Pada masa Hunter Gatherer, manusia pada masa itu tinggal di hunian yang sifatnya tidak permanen (nomaden). Membangun tenda menggunakan kain dan tongkat ataupun tinggal di gua. Mereka hidup dalam society atau kelompok kecil. Terdapat kegiatan memasak pada jaman ini, namun bersifat sangat sederhana dan hanya menggunakan api sebagai sumber energi untuk memasak. Agriculture Revolution mengubah kembali perilaku manusia dari yang nomaden menjadi menetap. Sehingga terjadi kembali perubahan keadaan arsitektur pada masa tersebut. Mulai terdapat pembagian atau klasifikasi fungsi dan kegiatan manusia sehingga mempengaruhi pembagian ruang arsitektur pada masa ini. Pada masa Industrial Revolution terjadi kembali perubahan keadaan arsitektur pada masa itu. Semua produksi dan pengolahan makanan sudah menggunakan alat bantu mesin. Hal ini dilakukan agar dapat menciptakan output makanan lainnya diluar kemampuan manusia. Bangunan-bangunan yang ada memiliki tipologi seperti factory/ mass production building yang dapat memuat kapasitas pekerja yang banyak dengan besaran ruang yang besar. Pada jaman sekarang makanan tidak hanya lagi dijadikan sebagai kebutuhan dasar manusia tetapi sudah menjadi bagian dari lifestyle generasi Millennial.

\section{METODE}

\section{Typology}

Metode ini digunakan untuk membantu proses penelitian isu yang akan diangkat di dalam proyek ini. Berikut di bawah ini adalah diagram kajian tipologi yang sudah dilakukan.

\footnotetext{
${ }^{9}$ Yuval Noah Harari -21 Lessons for the $21^{\text {st }}$ Century

${ }^{10}$ Lee, C., \& Jacoby, S. (2011). Typological Urbanism and The Idea of the City.

${ }^{11}$ Dear Millennials, - Dialogue Between Type and Behaviour

${ }^{12}$ Sapiens:a Brief History of Humankind - Yuval Noah Harari
} 

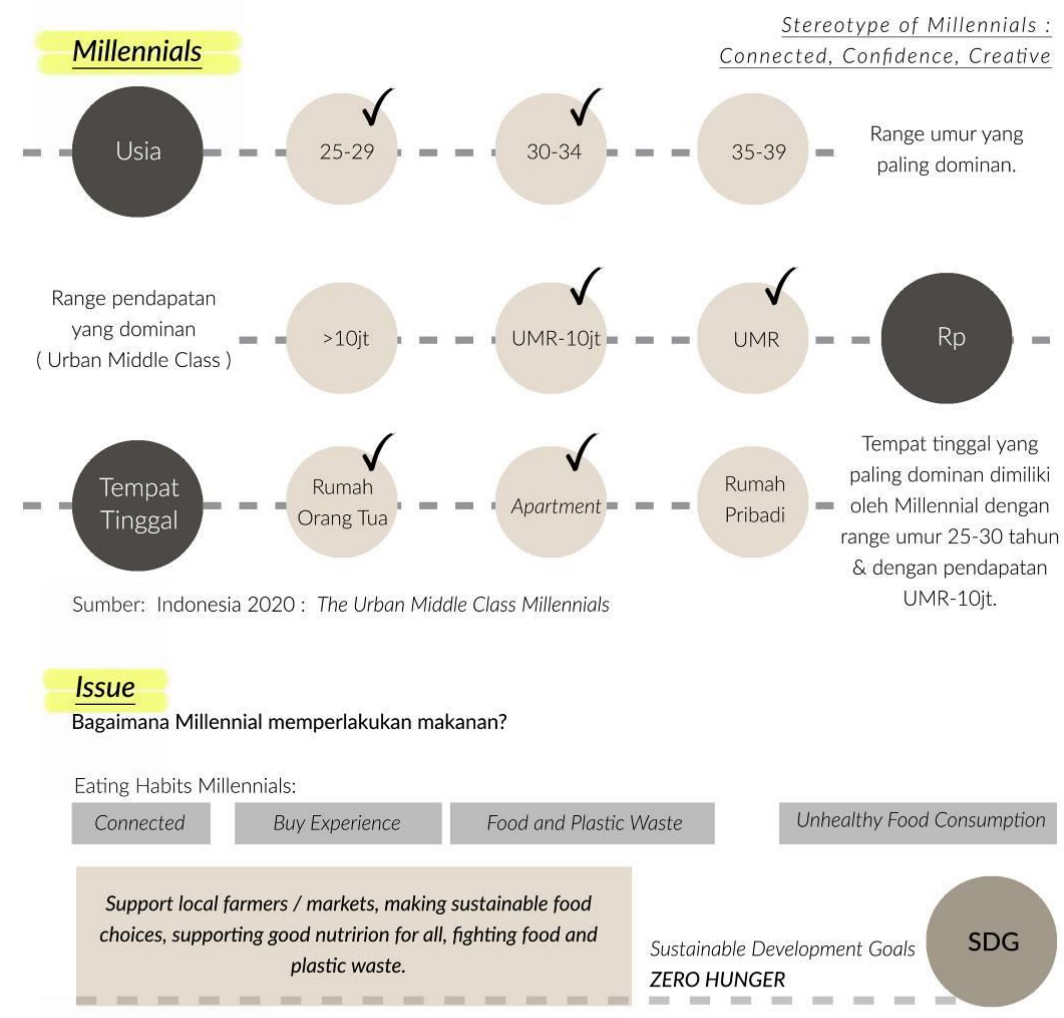

Eating Habits (berdasarkan kategori Millennial di atas)

\begin{tabular}{|c|c|c|c|c|c|c|c|}
\hline Usia & $\begin{array}{l}\text { Makar } \\
\text { Buy E) } \\
\text { Fast F } \\
\text { Conne } \\
\text { (Upda }\end{array}$ & $\begin{array}{l}\text { di luar } \sqrt{ } \\
\text { perience } \\
\text { od } \\
\text { cted } \\
\text { edi social media) }\end{array}$ & $\mathrm{Rp}$ & $\begin{array}{l}\text { Tertarik akan promosi } \\
\text { (diskon/free item) } \\
\text { Makan di luar } \\
\text { Affordable Price }\end{array}$ & $\begin{array}{l}\text { Tempat } \\
\text { Tinggal }\end{array}$ & \multicolumn{2}{|c|}{$\begin{array}{l}\text { Masak } \\
\text { Makan di luar } \checkmark \\
\text { Order food by apps }\end{array}$} \\
\hline \multirow[t]{5}{*}{ Places } & to go & \multirow{5}{*}{$\begin{array}{l}\text { Restaurant } \checkmark \\
\text { Cafe } \checkmark \\
\text { Food Court } \checkmark \\
\text { Warteg } \\
\text { Street Food } \\
\text { Food Stands } \checkmark \\
\text { PKL } \\
\text { Jajanan pasar }\end{array}$} & \multirow[t]{2}{*}{ Goals } & & \multicolumn{3}{|c|}{ Program Utama } \\
\hline & & & & & Restaurant & & Growing Field \\
\hline & & & \multirow{3}{*}{\multicolumn{2}{|c|}{$\begin{array}{l}\text { "Menjadi tempat makan, kerja, } \\
\text { dan santai bagi Millennial serta } \\
\text { dapat menjadi motor penggerak } \\
\text { untuk memperbaiki eating habits } \\
\text { Millennial. }\end{array}$}} & $\begin{array}{l}\text { Cafe } \\
\text { Food Stands }\end{array}$ & 1. & Area \\
\hline & & & & & Education & & Sustainable Food \\
\hline & & & & & Area & 2 & $\begin{array}{l}\text { Utensils } \\
\text { Shop }\end{array}$ \\
\hline
\end{tabular}

Gambar 1. Diagram Kajian Tipologi

Sumber: Penulis, 2019

\section{Studi Lapangan}

Metode ini digunakan untuk membantu peneliti menganalisis tapak terpilih. Pada tanggal 3 Januari 2019 pukul 11.05 WIB dilakukan pengamatan fisik dan kegiatan (observasi) di sekitar site terpilih. Survei lapangan dilakukan kembali pada hari Rabu, 16 Februari 2019 di Pantai Indah Kapuk pukul 12.30 WIB. Dengan parameter membawa isu yang diangkat yaitu "Bagaimana Millennials memperlakukan makanan?". Survei dilakukan di 2 jenis tempat yang berbeda yaitu Food Court PIK Avenue Mall, dan Café \& Restaurant di sekitar Pantai Indah Kapuk. Hasil kesimpulan dari survei lapangan 3 Januari 2019 adalah site dekat dengan Office \& Apartment Gold Coast, Fresh Market PIK, Market City PIK, Yayasan Tzu Chi, Perumahan Gold Coast, PIK 2, PIK Avenue Mall, Mercure Hotel, dan lainnya. Keadaan eksisting site merupakan ruko sewa yang memiliki variasi pelayanan jasa dan barang yang ditawarkan. Memiliki mobilitas kendaraan yang mudah mudah dicapai dan pergerakan pedestrian yang ramai sepanjang hari di sekitar tapak. Terdapat fasilitas transportasi umum yang memadai. Keadaan cuaca cukup panas pada siang hari, tetapi berangin karena dekat dengan laut. Site berada jauh dari titik kemacetan pada jam padat. Hasil kesimpulan dari survei lapangan 16 Februari 2019 
adalah generasi Millennial di Food Court PIK Avenue Mall banyak yang tidak menghabiskan makanan dan meninggalkan sampah plastik. Generasi Millennial di The Garden PIK banyak yang mengabadikan momen dengan mengambil foto atau video pada tempat ini untuk diunggah di social media. Generasi Millennial di Starbucks PIK banyak bekerja menggunakan gadgetnya, namun banyak ditemukan sampah plastik.

\section{Pattern Languange}

Metode ini digunakan untuk membantu menemukan program ruang dan analisis keterkaitan hubungan antar program tersebut. Bangunan ini memiliki lima program utama yang dibagi menjadi dua bagian yaitu sebagai implementasi konsep utama rancangan dan sebagai bentuk tanggapan terhadap hasil analisis lokasi tapak. Empat program utama tersebut adalah Restaurant \& Café, Growing Field Area(Gardening), Education Platform dan Sustainable Food Utensils Shop. Satu program utama lainnya adalah menjadikan tapak sebagai linkage kota. Berikut di bawah ini adalah diagram analisis Pattern Language.

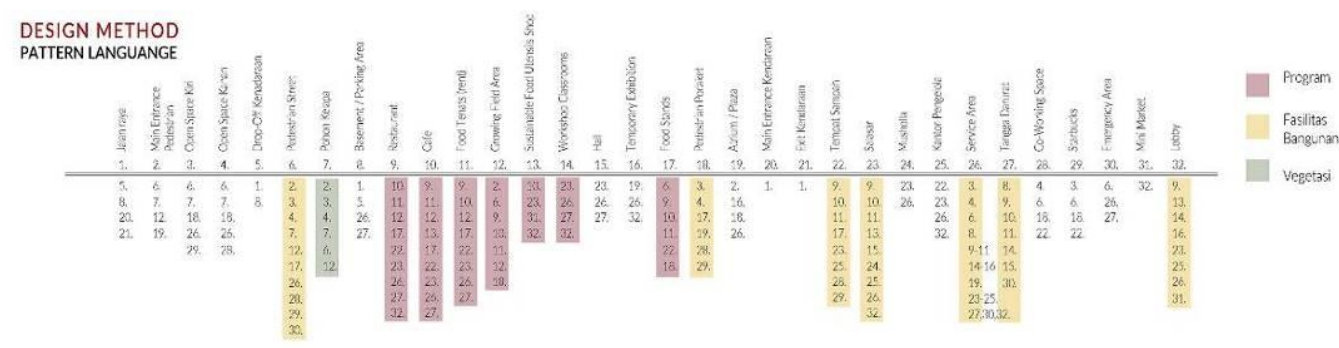

Gambar 2. Diagram Analisis Pattern Language

Sumber: Penulis, 2019

\section{Phenomenology}

Metode ini digunakan untuk membantu peneliti mendesain keruangan bangunan dengan mengacu pada konsep utama yaitu Sustainable Eating Habits in Millennials. Phenomenology lebih digunakan di dalam rancangan interior, penggunaan material dan pengaturan cahaya serta bayangan. 


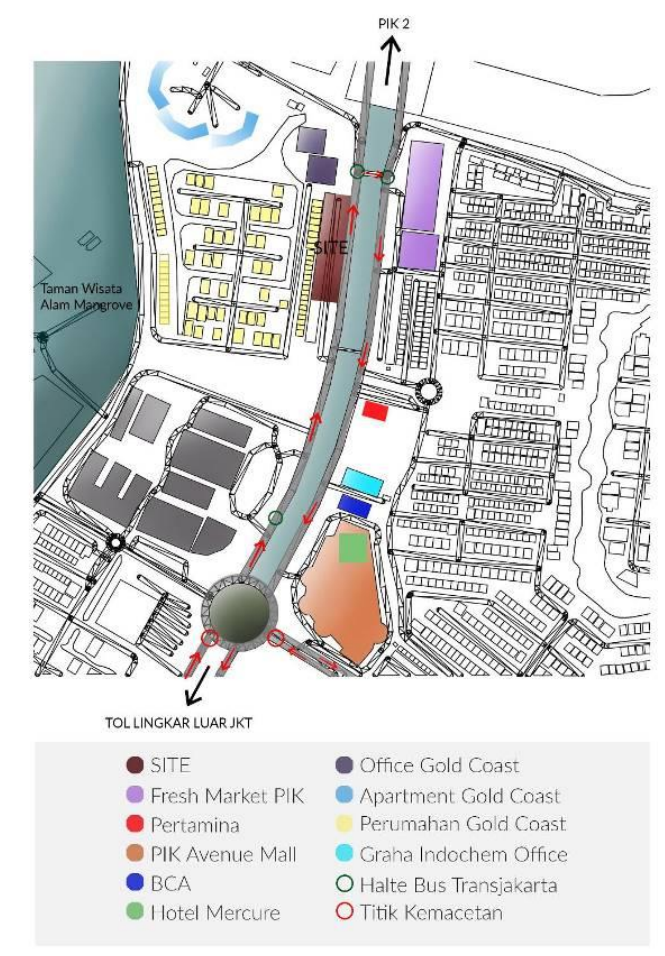

Gambar 3. Pemetaan Fungsi Bangunan di Sekitar Site Sumber: Penulis, 2019

\section{DISKUSI DAN HASIL}

Proyek ini dinamakan sebagai Pusat Kuliner Berkelanjutan di Pantai Indah Kapuk/ Sustainable Food Hub at Pantai Indah Kapuk dengan konsep dasar Sustainble Eating Habits in Millennials yang berisi program yang mendukung perubahan eating habits generasi Millennial menjadi lebih mendukung gerakan Sustainable Development Goals perihal Zero Hunger, menjaga kualitas ekologi yang lebih baik dengan mengurangi sampah makanan dan plastik serta menjadikan bangunan ini linkage sebagai bentuk kontribusi proyek terhadap kota.

Berdasarkan gambar di atas, proyek ini berada di Jl. Pantai Indah Kapuk bersebelahan langsung dengan Office Gold Coast, Gold Coast Residence dan Market City PIK. Daerah PIK terkenal sebagai ikon pusat kuliner di Jakarta Utara sehingga posisi site sangat sesuai dengan fungsi bangunan pada proyek ini. Pergerakan mobilitas pedestrian di sekitar tapak sangat ramai sedangan tapak tidak menyediakan jalur pedestrian. Maka dari itu salah satu bentuk kontribusi tapak terhadap kota adalah dengan menjadikan sebagaian luas tapak linkage kota. Namun site tetap memiliki beberapa konflik yaitu bentuknya yang memanjang sehingga menyulitkan proses desain, memiliki kualitas iklim yang cenderung berangin kencang, panas dan lembap dikarenakan dekat dengan pantai dan laut serta harga tanah yang mahal dan kualitas tanah yang kurang baik karena awalnya berupa rawa dan hutan bakau. Site memiliki peraturan pemerintah yaitu memiliki luas tapak $6.800 \mathrm{~m}^{2}$ dengan besaran proyek sekitar $13.433 \mathrm{~m}^{2}$. Memiliki tinggi bangunan maksimal 4 lantai dengan peruntukan perdagangan dan jasa. Daerah hijau sebesar $2.205 \mathrm{~m}^{2}$ (KDH 35\%), luasan dasar bangunan maksimal sebesar $3.150 \mathrm{~m}^{2}$ (KDB 50\%) dan luasan basement maksimal sekitar $3.150 \mathrm{~m}^{2}$ (KTB 50\%). GSB pada bangunan ini sebesar $7 \mathrm{~m}$. 


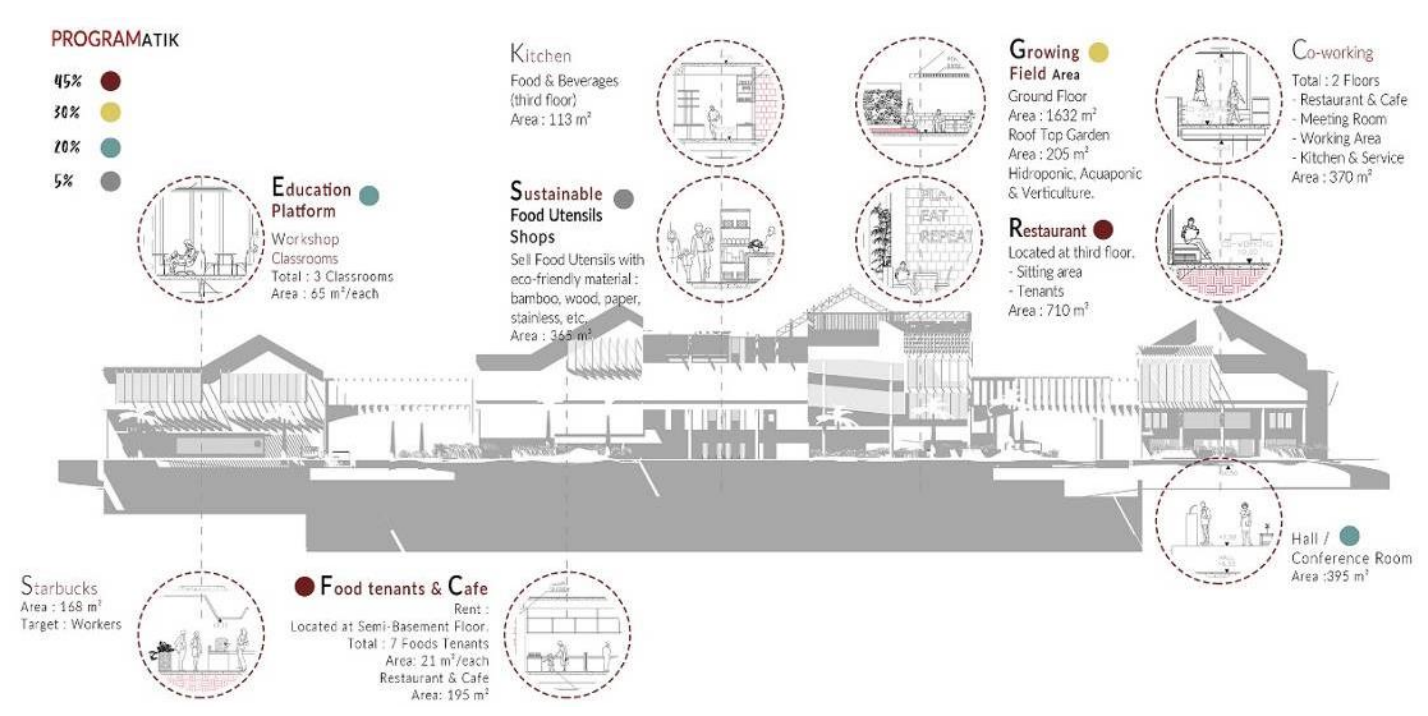

Gambar 4. Diagram Peletakan Program pada Bangunan Sumber: Penulis, 2019

Berdasarkan gambar di atas, program ini terdiri dari lima program utama yang dibagi menjadi dua bagian yaitu empat program utama sebagai hasil implementasi dari konsep Sustainable Eating Habits in Millennials dan satu program utama sebagai hasil analisis tapak dan bentuk tanggapan terhadap kota. Empat program utama Sustainable Food Hub adalah Restaurant \& Café, Sustainable Food Utensils Shops, Growing Field Area (Gardening) dan Education Platform. Satu program utama kontribusi Sustainable Food Hub terhadap kota adalah Linkage.

Setelah itu, digunakan metode Pattern Languange untuk menentukan hubungan antar program pada proyek ini. Hubungan tersebut berkaitan dengan proses perancangan gubahan massa yang akan terjadi. Selain itu, melalui proses analisis dengan menggunakan metode Pattern Languange, akan terlihat program yang memiliki hubungan dengan program-program lainnya yang paling utama. Berdasarkan hasil analisis program menggunakan Pattern Language, dapat dilihat bahwa program Linkage menjadi pengikat semua program lainnya. Dilanjutkan oleh empat Program Utama yaitu Restaurant dan Café, Growing Field Area, Education Platform dan Sustainable Food Utensils Shop. Masing-masing empat program utama memiliki area tersendiri yang akan dibagi di dalam gubahan massa bangunan sesuai dengan kebutuhan dan design ideas yang ada. Fasilitas pelengkap lainnya yang paling dibutuhkan adalah Lobby, Emergency Area, dan Service Area sehingga peletakan fasilitas-fasilitas tersebut akan berdekatan dengan pusat-pusat kegiatan di dalam bangunan ini.

Setelah hubungan antara program ruang sudah didapatkan, maka proses selanjutnya adalah merancang gubahan massa. Massa dibagi menjadi empat bagian dengan penyesuaian dengan kondisi site dan analisis program ruang. Berikut di bawah ini adalah diagram proses gubahan massa. 


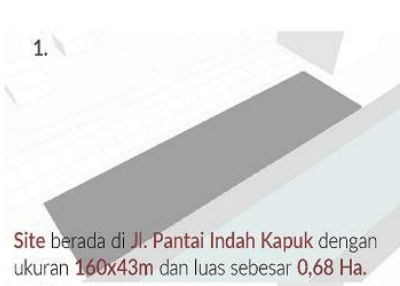

$$
4 .
$$

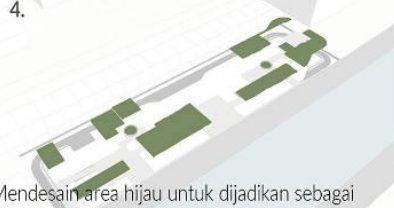

Growing Field Area.

$$
7 .
$$

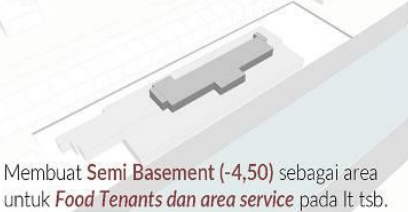
untuk Food Tenants dan area service pada it tsb. 10.

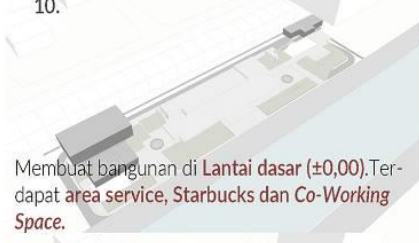

13.

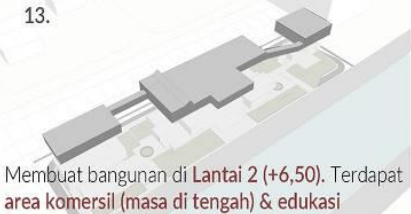
area komersil (masa di tengah) \& edukasi (samping kanan dan kiri) .

$$
16 .
$$

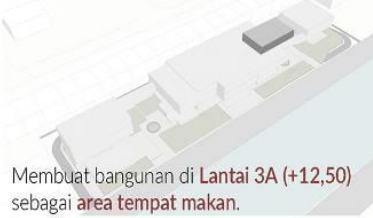

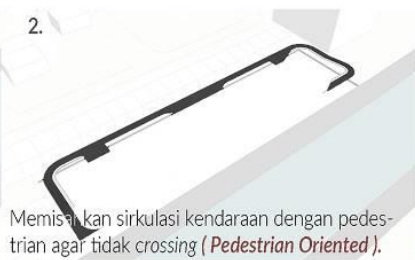

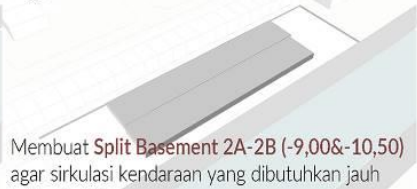

aoar sirkulasi kendaraan yang dibutuhkan jauh lebih efektif.

$$
8 .
$$

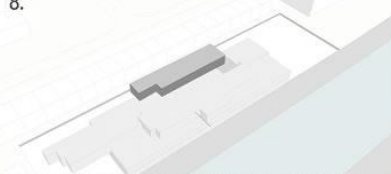

Membuat Semi Basement $(-2,50)$ sebagai area untuk Lobby dan area makan.

11.

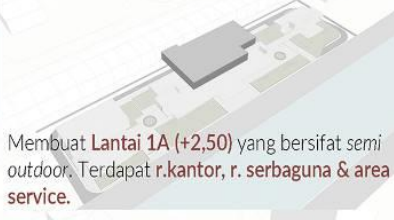

14.

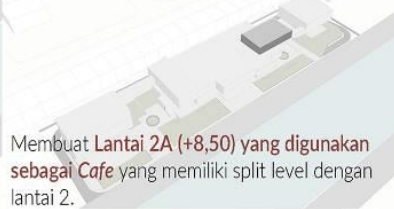
lantai 2.

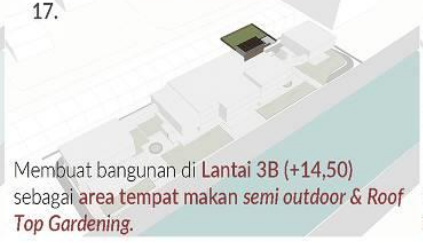

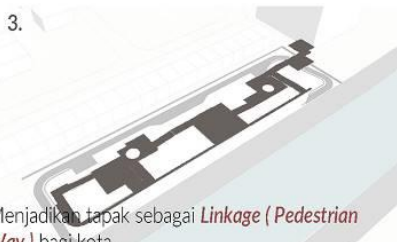

Way) bagikota.

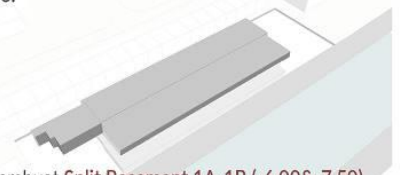

Membuat Split Basement 1A-1B $(-6,00 \&-7,50)$ dan area untuk service $(-6,00)$.

9.

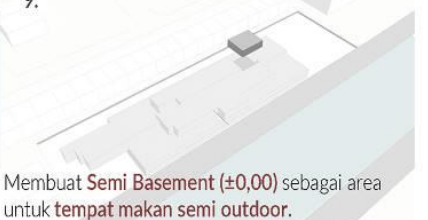

12.

Membuat Lantai $1 \mathrm{C}(+4,50)$ yang digunakan sebagai Sustianable Food Utensils Shop. Memiliki split level dengan lantai $1 \mathrm{~A}$.

15.

Membuat Lantai $3(+10,50)$ sebagai area untuk tempat makan ( Restaurant, Kitchen \& Service).

18.

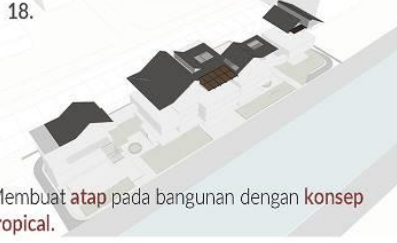

Gambar 5. Proses Gubahan Massa Bangunan

Sumber: Penulis, 2019

Setelah proses gubahan massa selesai, berikut di bawah ini adalah diagram axonometri exploded denah pada proyek ini. Pada gambar di bawah ini akan dijelaskan mengenai pengelompokan ruang tiap lantai sesuai dengan fungsinya. Bangunan ini memiliki beberapa design ideas yaitu millennials desires, split levels, pedestrian oriented, dan sustainable. Bangunan ini menjadi tempat di mana Millennials dapat melakukan berbagai aktivitasnya dalam suatu tempat dan waktu yang sama. Banyak sekali menggunakan split levels di mana bisa menghadirkan pengalaman ruang yang menarik. Mementingkan pedestrian sebagai pengguna utama pada bangunan ini sehingga memisahkan sirkulasi kendaraan dengan sirkulasi pedestrian agar tidak crossing. Bangunan ini menerapkan kata sustainable yang diaplikasikan pada program bangunan dan desain bangunan ini. 


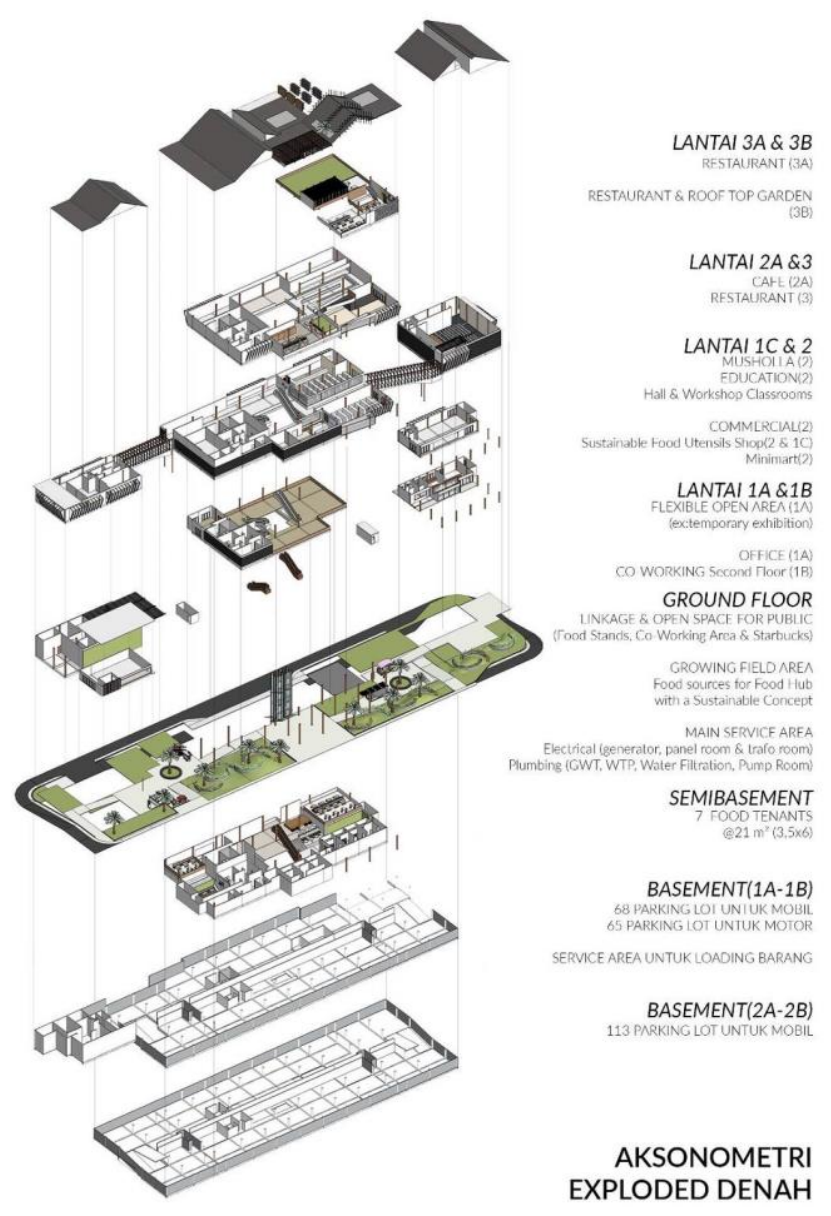

Gambar 6. Aksonometri Exploded Denah Sumber: Penulis, 2019 
Berikut di bawah ini adalah gambar fasad bangunan. Bisa dilihat pada fasad bahwa bangunan ini mengangkat kesan tropis dengan jenis bangunan landed yang memiliki fungsi sebagai bangunan komersil. Memiliki atap pelana dengan sentuhan aksen repitisi secara vertikal pada fasad sehingga memberikan kesan tinggi pada bangunan ini. Dapat dilihat juga pembagian ruang indoor dan semi outdoor pada fasad. Pada ruang semi outdoor lebih menonjolkan struktur bangunan. Bangunan ini lebih mengutamakan penggunaan material dinding bata, atap aspal dengan struktur atap baja ringan, kaso baja ringan sebagai tralis jendela dan kaca tempered untuk bukaan kaca.

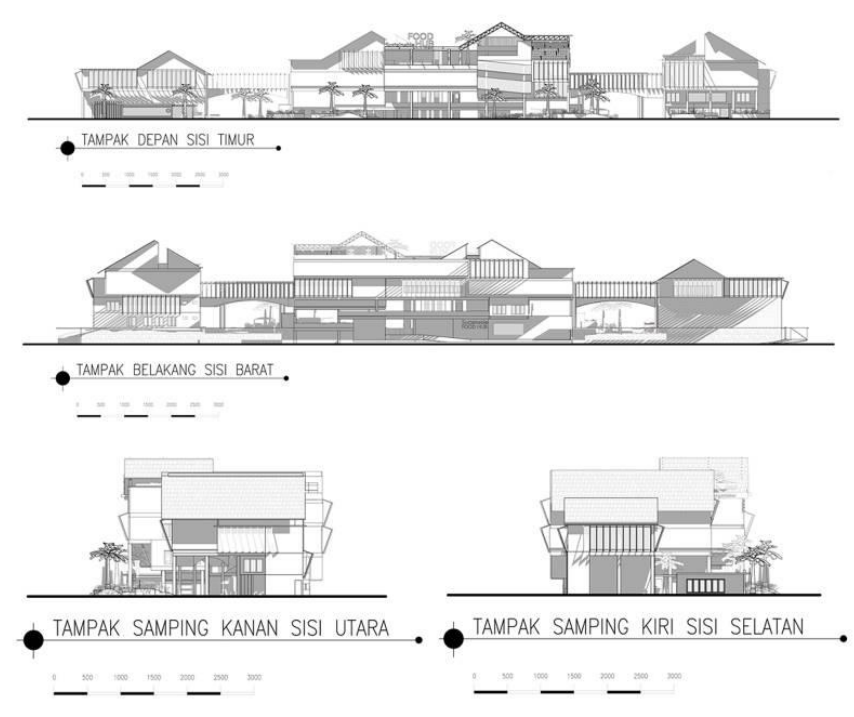

Gambar 7. Fasad Bangunan

Sumber: Penulis, 2019

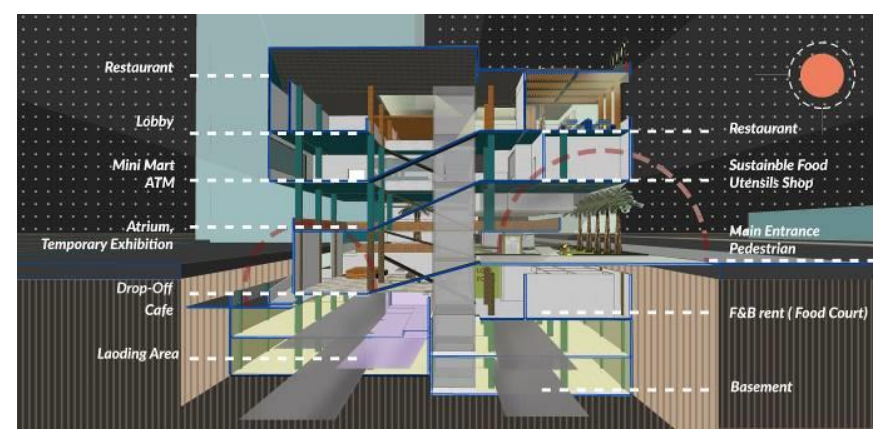

Gambar 8. Potongan Perspektif Bangunan

Sumber: Penulis, 2019

Pada gambar potongan dan potongan perspektif di bawah ini, dapat dilihat bahwa bangunan ini memiliki banyak pembagian split level. Memiliki orientasi utama terhadap pedestrian sehingga main entrance utama di bagian depan khusus untuk pedestrian sedangkan drop-off kendaraan berada di belakang bangunan. Memisahkan sirkulasi pedestrian dan kendaraan agar tidak crossing. Memiliki 3 gubahan massa yang disusun secara linear dengan jembatan sebagai penghubung. Memiliki void di massa utama sehingga memberikan kesan adanya hubungan ruang tiap lantai. 


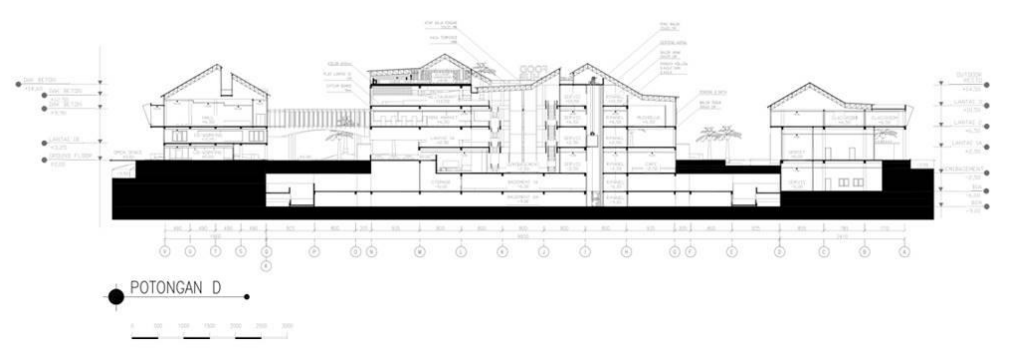

Gambar 9. Potongan Bangunan

Sumber: Penulis, 2019

Berikut di bawah ini adalah gambaran suasana bangunan melalui perspektif eksterior maupun interior. Pada malam hari, bangunan ini memanfaatkan LED sebagai media komunikasi visual sehingga bangunan ini tetap hidup. Lalu pada siang hari di dalam tapak dapat digunakan sebagai linkage kota, disertai dengan food stands dan open space. Restaurant dan Café pada bangunan ini memanfaatkan suasana semi-outdoor dengan kesan homey sehingga Millennial dapat melakukan banyak aktivitas pada bangunan ini.
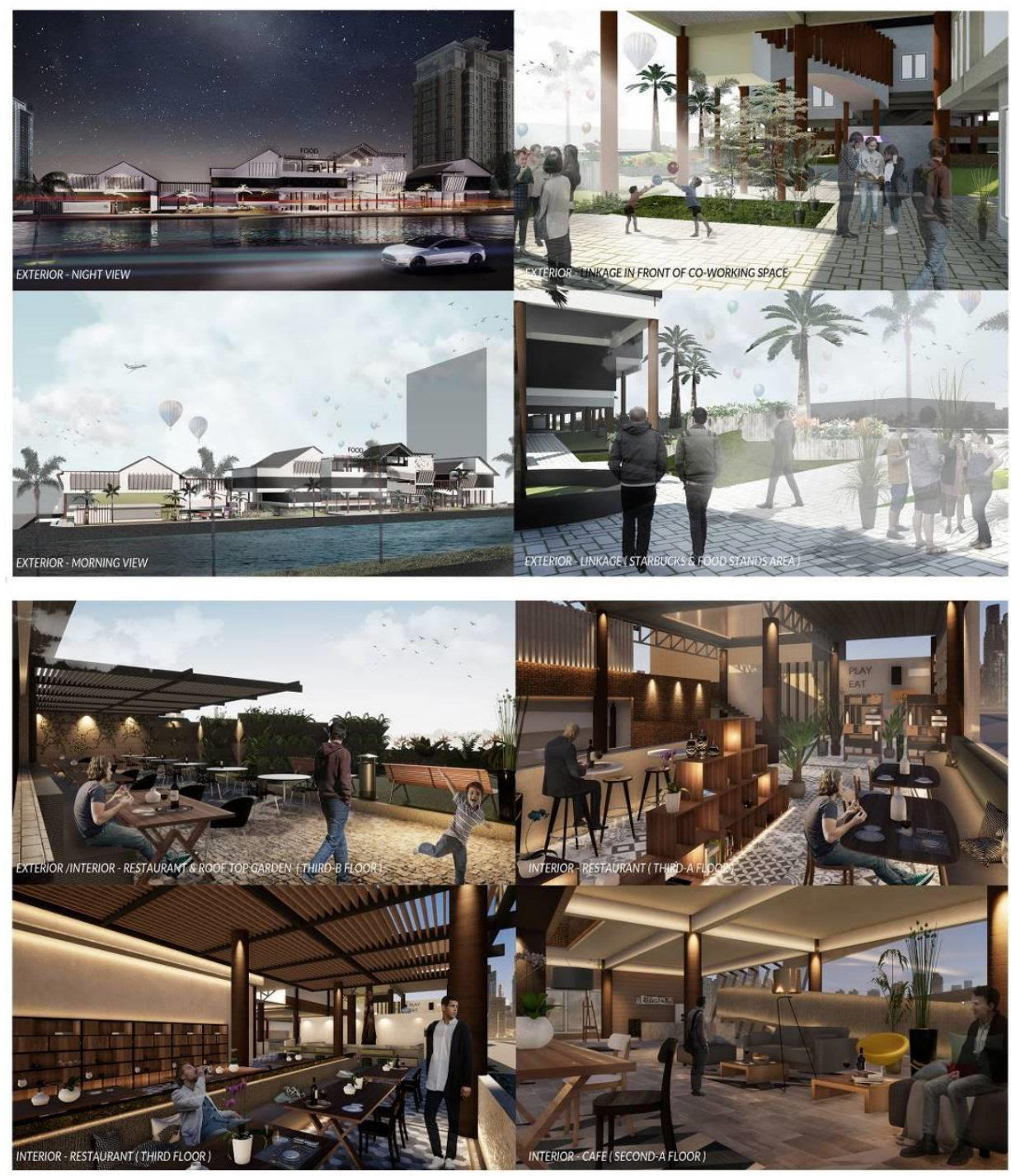

Gambar 10. Perspektif Eksterior dan Interior Bangunan Sumber: Penulis, 2019 


\section{KESIMPULAN DAN SARAN \\ Kesimpulan}

Millennial memperlakukan makanan dengan empat kebiasaan utama yaitu Connected, Buy Experience, Food and Plastic Waste dan Unhealthy Food Consumption. Hal tersebut tentunya memberikan dampak baik dan buruk bagi diri sendiri maupun lingkungan sekitar. Melalui hasil riset yang sudah dilakukan, Eating Habits in Millennial perlu dikaji lebih lanjut sehingga menjadi lebih sustainable. Hal ini dipengaruhi oleh permasalahan dunia perihal Zero Hunger $S D G$ dan kualitas ekologi yang menurun akibat peningkatan sampah plastik dan makanan. Maka konsep utama pada proyek ini adalah Sustainable Eating Habits in Millennial. Melalui konsep tersebut terbentuklah hasil desain bangunan yang dinamakan Pusat Kuliner Berkelanjutan di Pantai Indah Kapuk / Sustainable Food Hub at Pantai Indah Kapuk.

Bangunan ini memiliki lima program utama yang dibagi menjadi dua bagian yaitu bentuk implementasi dari konsep utama perancangan dan bentuk tanggapan terhadap analisis tapak terpilih. Empat program utama adalah Sustainable Food Hub adalah Restaurant \& Café, Sustainable Food Utensils Shops, Growing Field Area (Gardening) dan Education Platform. Satu program utama kontribusi Sustainable Food Hub terhadap kota adalah Linkage. Proyek ini memiliki tujuan yaitu dapat memberikan kontribusi bagi kota dengan mengubah eating habits Millennial menjadi lebih peka terhadap isu dunia yaitu Zero Hunger-SDG, menjaga kualitas ekologi kota dan membantu menyediakan kebutuhan jalur pedestrian di sekitar tapak.

\section{Saran}

Lebih banyak mengimplementasikan konsep Sustainable pada bangunan ini agar lebih maksimal. Dapat menambahkan kapasitas ruang pada beberapa program utama agar dapat memaksimalkan kapasitas pengunjung yang datang. Dapat menganalisis lebih dalam setiap tenant makanan yang akan dijual di bangunan ini agar beda dari yang lain dan sesuai dengan konsep perancangan.

\section{REFERENSI}

Akhmad, M. (2018). Saksikan: Begini Kerennya Jalur Pedestrian di Jalan Thamrin, diunduh 9 Februari 2019, <https://www.idntimes.com/news/indonesia/akhmadmustaqim/saksikanbegini-kerennya-jalur-pedestrian-di-jalan-thamrin/full

Massie, C. (2014) Study: Millennials' Impact on Workplace Design and Urban Planning, diunduh 30 Januari 2019, <https://www.architectmagazine.com/design/urbanismplanning/study-millennials-impact-on-workplace-design-and-urban-planning_o

Bas, F. (2018). Anatomi Pemikiran Michel Foucault: Wacana dan Kekuasaan (Discourse and Power) di http://febasfi.blogspot.com/2013/07/anatomi-pemikiran-michel-foucault.html (diakses 27-10-2018)

Harari, Y. N. (2014). Sapiens:a Brief History of Humankind. Canada: McClelland \& Stewart.

Harari, Y. N. (2017). Homo Deus a Brief History of Tomorrow. Canada: HarperCollins Canada.

Harari, Y. N. (2018). 21 Lessons for the 21st Century. New York: Spiegel \& Grau.

Indrawati, K. P. (2018), Menyoal Kebebasan, Kreativitas, dan Etika: Refleksi Kegelisahan Berpengetahuan Arsitektural di Jagat Infonaut, diunduh 27 Desember 2018, <http://membacaruang.com/menyoal-kebebasan-kreativitas-dan-etika/

Lee, C., \& Jacoby, S. (2011). Typological Urbanism and The Idea of the City. London: Wiley.

Lobell, M. (1983). Spatial Archetypes: The Hidden Patterns of Psyche and Civilization.

California: CreateSpace Independent Publishing Platform.

Sutanto, A. (2018). Dear Millennials, Dialogue Between Type and Behaviour. Jakarta: Universitas Tarumanagara.

National Geographic Indonesia. (2018). Sejarah Pelabuhan Sunda Kelapa dan Cikal Bakal Kota Jakarta, diunduh 18 Januari 2019, $<$ http://nationalgeographic.grid.id/read/13886122/sejarah-pelabuhan-sunda-kelapa-dancikal-bakal-kota-jakarta?page=all 
Purwandi, L. (2016). Indonesia 2020: The Urban Middle Class Millennials di https://www.researchgate.net/publication/314448735_Indonesia_2020_The_Urban_Middl e_Class_Millenials

Sandbergs, A. (2009). Diagram Arketipe Spasial “Jaringan" di Era Para Infonaut.

Sristia, T. (2009). Konsep MRT ( Mass Rapid Transit ) Sebagai Penerapan Pembangunan Transportasi Berkelanjutan, diunduh 9 Februari 2019, <http://trisnasristia.blogspot.com/2009/04/konsep-mrt-mass-rapid-transit-sebagai.html

Sustainable Development Goals. (2018). Goal 2: Zero Hunger, diunduh 9 Januari 2019, <https://www.un.org/sustainabledevelopment/hunger/

Talks at Google. (2018). Yuval Noah Harari: "21 Lessons for the 21st Century", diunduh 27 Desember 2018, <https://www.youtube.com/watch?v=Bw9P_ZXWDJU

Wolfram, T. (2019). Sustainable Eating, diunduh 9 Januari 2019, <https://www.eatright.org/health/lifestyle/culture-and-traditions/sustainable-eating 
